\title{
Latest Application of Mixed Media in Modern Sculpture
}

\author{
Luo $\operatorname{Jin}^{1, \text { a }}$ \\ ${ }^{1} \mathrm{Rm} .106$, NO.17 Building, Teacher's Dorm at South Gate, Old District, Jingdezhen Ceramic \\ University, China \\ aluojin0798@163.com
}

Keywords: mixed media, modern sculpture, visual art

Abstract. Application of mixed media in modern sculpture implies a broad scope, and this paper just studies it in terms of modern art sculpture. This article researches current status of modern domestic and international mixed-media sculpture, and by analyzing and understanding works designed by part of the domestic and foreign related artists, points out that in artistic creation, appropriate use of the different materials can make the sculpture works to obtain a rich and strong visual effect.

\section{Introduction}

With the diversification and economic development of society, sculptural creation is influenced by the strong impact of various factors. In a world of advanced media technology, many deep things seem be drowning in superficial prosperity. In order to express the inherent necessity of their artworks, more and more sculptors employ a variety of different materials in their artistic creation. Some avant-garde sculptors even turn to sound, light, electric technology, so the choice of material is very important.

\section{Definition of mixed media.}

All substance that can be thought of or found can be referred to as material. It includes virtual, conceptual material, etc. Mixed media takes materials as breakthrough, and shifts in sculptural process led to an almost complete freedom of materials and process. A wide variety of materials may be employed and constitute an artwork. In the making of an artwork, clay, glass, steel, wood, stone and chemical reagent may be employed. In western countries, these materials are called as mixed media.

\section{Aesthetics of materials}

There is close relationship between material and human beings. And in our daily life, material plays a very important role. With the development of modern art, almost all kinds of materials can be used in the creation of sculpture. So the research on the physical beauty of material is very important.

Sense of reality of materials. The sense of reality of materials is a kind of beauty of the material itself. It mainly expresses intrinsic characteristics of the material, for instance, the weight, temperature, dry or wet, soft or hard, and so on. Various different characteristics will produce different tactile, visual and sensory stimulation. This is the irreplaceable aesthetic attribute of the material.

Texture of materials. The texture of material, through shape, structure and texture of surface, gives people the expression of visual and touch, aesthetic experience and symbolize sense. For example, for the bronze sculpture "walking man I", Swiss sculptor Alberto Giacometti applied plaster directly on the support structures. After bronze casting, this mottled texture and peculiar shape create an odd and mysterious atmosphere which is detached from surroundings. The unique sense of reality and texture aesthetic features of different materials build more profound connotation of artworks. So, this requires that sculptors have higher aesthetic cultivation, as well as deeper understanding to the material properties and characteristics, and certain sculpture skills.

Psychological implications of materials. The physical properties of the material have psychological implications. For example, delicacy, fineness and high gloss of "porcelain" make people feel women's beauty, sweetness, gentleness and quietness. Instead, "ceramic" roughness, oldness and vicissitudes are associated with men's heaviness, bitterness, difficulty and powerfulness. It is absolutely not elegant and supple, but really raw and wild. Just as rust freezes on bronze, welding spots flash on welded metal, and knife marks hop into wood and stone, in the process of artistic activities, they reflect 
physical properties of materials, record the process of making sculptures, and enrich characteristics of material media. All these would be viewers' first impression on materials.

\section{Current status of modern domestic and international mixed-media sculpture}

The rapid development of social science and technology changes and refreshes people's understanding of art. With the emergence of mixed media, creators are not satisfied with using traditional single material, and begin to look for and try new materials.

Current status of international mixed-media sculpture. Mixed media have found wide application in western countries. Different materials convey different spiritual connotation. According to actual need, sculptors select various mixed media to explore and practice artistic liberty. It is a job full of joy and challenge.

For example, great Italian Impressionist Medardo Rosso, who created considerable amounts of mixed-media sculptures, opened up a new way to application of mixed media in modern sculpture. He commonly used wax as his primary sculpture material, and he pioneered the study of characteristics of the contemporary experimental sculpture.

And again, as outstanding exponent of cubism, both Archipenko Alexander and Jacques Lipchitz are pioneers of mixed-media sculpture. They used wood, glass, metal, plaster as their sculpture material, and regarded sculpture as construction of space, instead of traditional amount of space occupied.

Moreover, Marcel Duchamp, whose work is associated with Cubism, conceptual art and Dada, often assembled ready-made things, such as comb, shovels and bicycle wheel, by changing their location and environment, to make people have a sense of great surprise.

Current status of domestic mixed-media sculpture. In the1980s, it was still a virgin field in application of materials in China. In the late 90's, Chinese artists realized the importance and aesthetic value of materials in sculpture creation, and began to explore and research application of materials.

Here author would like to mention three practitioners of materials in the Chinese sculpture field: $\mathrm{Xu}$ Bing, Sui Jianguo and Lv Pinchang.

$\mathrm{Xu}$ Bing, one of the world's most creative contemporary artists, believes that the relationship between materials and artists is essentially a source of inspiration. From the large-scale sculpture "phoenix" (Figure 1) can be seen, Xu Bing's choice for materials will not only satisfy her most fastidious demand, but also have highly cultural taste. Assembled with earth drilling machine, excavator, safety helmet, shovels, metal drums and other construction waste, this sculpture reflected Nirvana reborn of waste and metaphorical relation of garbage and wealth, also displayed realism, politics and profound moral.

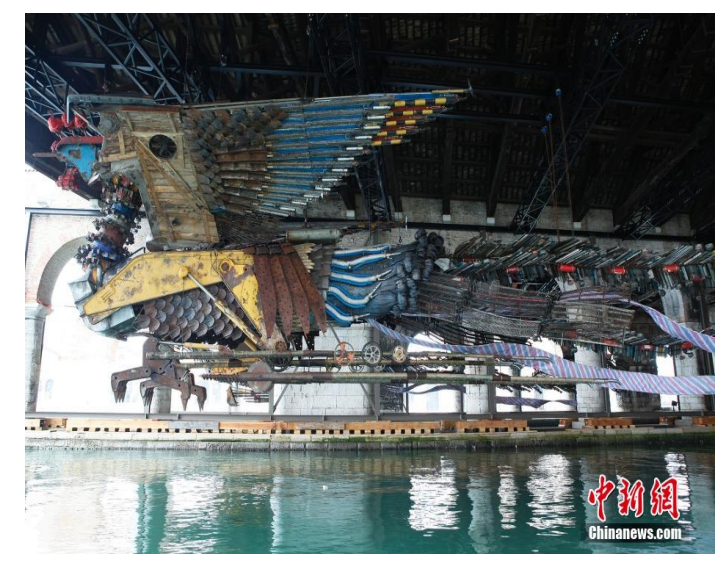

Fig.1 Xu Bing phoenix

Sui Jianguo, known as "the earliest and farthest Chinese sculptor on the road of ideastism", insists on contemporary form exploration in the artistic creation and focuses on application of mixed media. Sculpture "gravitational field" (Figure 2) does not use bronze, which can reflect loftiness and solemnity of sculpture, as its material. Instead, it employs fragile, less durable plaster, and uncontrollable 
polyurethane. These cheap and congenitally defective materials, through Sui's redesign, obtain their dignity and glow with bright beauty.

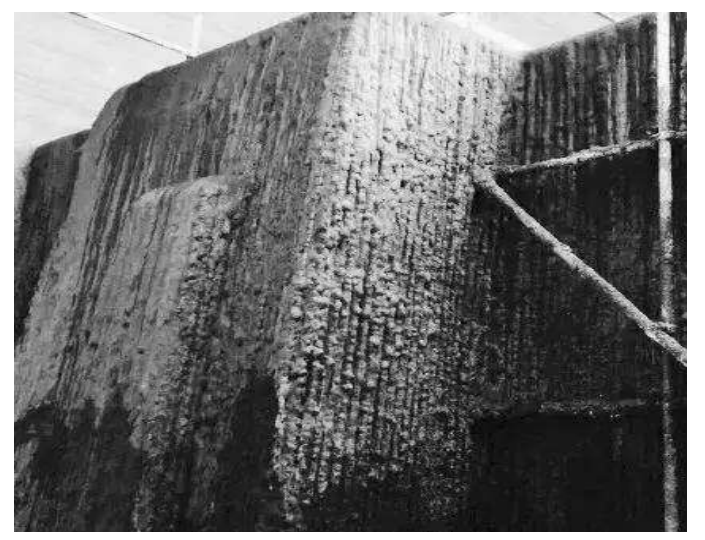

Fig.2 Sui Jianguo gravitational field

Lv Pinchang, professor and chairman of the Department of Sculpture in Central Academy of Fine Arts in Beijing, is a contemporary Chinese artist. His sculpture "Sunrise of Poyang Lake" (Figure 3) creatively uses LED surround video technology, also in a completely new way expresses the relationship between the public and public space, and effectively expands the sculpture's expressive space. The sculpture focuses on readability in an interactive manner. Light and music inside the sculpture, is an expressing means for this sculpture, and they even become major sculptural materials. The function of material in the sculpture is statement and expression. It is statement of material surface, and also is hearts' expression. Obviously, contagious material not only enhances the tension of mixed media to the modelling spirit, it is also a driving force to develop the creative thinking of artists.

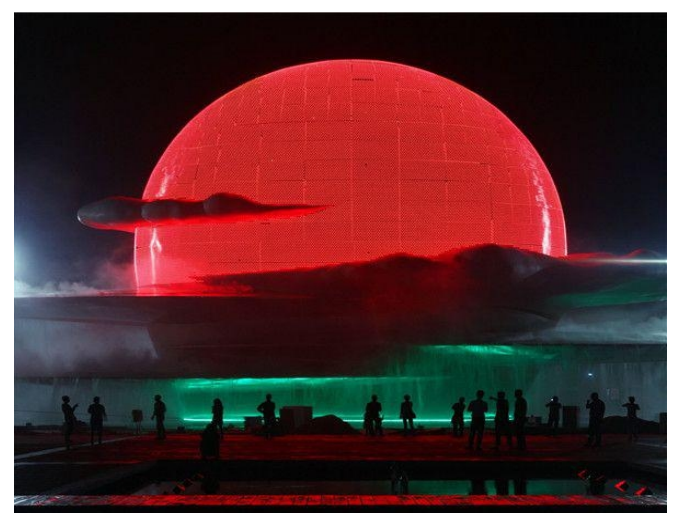

Fig.3 Lv Pinchang Sunrise of Poyang Lake

\section{Experimental applications of mixed media}

Every new discovery, experiment and application of new mixed media in modern sculpture, means to create a new visual language.

The importance of correct choice of materials, and the different visual expression it brings, should not be underestimated. For example, Geng Xue's "An Unfinished Slave" (Figure 4), in the form of images, completely shows us how to create a clay sculpture from beginning to end. As the artist breathed her life with kisses into his lips mouth to mouth, she presented a moving scene for all of us. After that, the clay man's chest began to be lifted up and down with every breath. He seemed to be alive. This work produces a much stronger visual impact than a static display of clay sculpture. Why? Because the audience can not only understand the production process, but also feel the reality of materials, such as soft or hard, as if you are touching it. This is why mixed media can often achieve the outstanding artistic effects beyond the shape of sculpture itself. 


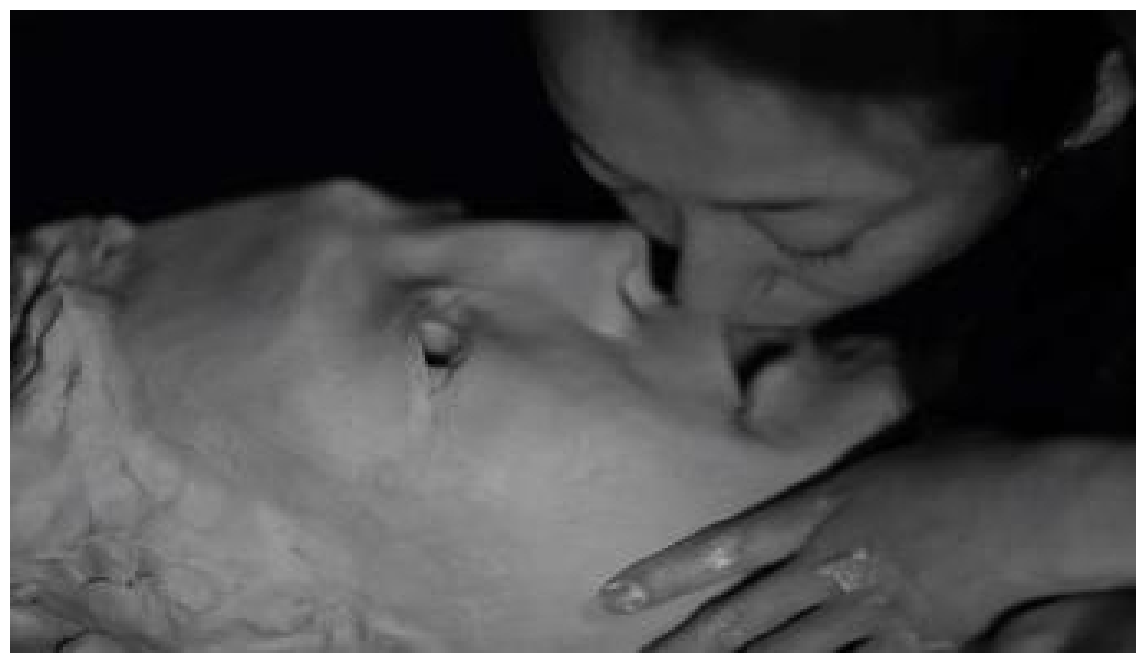

Fig.4 Geng Xue An Unfinished Slave

In addition, since material itself contains aesthetic value, the texture of different materials gives people different visual effects. So, material is an important medium to express the real emotions of a sculptor, who is able by virtue of imagination and talent to create works of aesthetic value, especially in the fine arts. As abstract expressionism master Kandinsky once said," every work of art is the child of its age and, in many cases, the mother of our emotions. It follows that each period of culture produces an art of its own which can never be repeated", in the field of contemporary art, object and subject have undergone fundamental changes, and materials have been transformed into a special form of cultural expression. Contemporary Chinese sculptor Zhan Wang's “Artificial Jiashanshi series" [1], also known as Scholar Rocks, which he started creating in 1995, is the transcendence of materials, as well as the presentation of his concepts. He places both the actual rocks and their stainless steel versions together, and there is a remarkable contrast between them. He tries to express that we should be alert to human-environment relationship. It can be seen that, application of materials reflects the sculptor's unique creative language and artistic expression. At this time, material is not only a medium in the process of the artistic creation, but also sometimes even become a specific expression of the spirit of works.

\section{Conclusions}

Modern sculpture art should pay more attention to the experimental application of mixed media. Through these media, sculptures can provide newer, more modern artistic language forms which are close to life. Of course, the experimental application of mixed media is not arbitrary. It is thinking and practice in sculpture modelling and material selection, which realize sculptor's creative ideas, and accurately express the themes of works. Only when sculptors' personal experience corresponds with the content of the artists' works, the creative expression of mixed media in modern sculpture results the moving art power. Therefore, sculptors should expand the application of mixed media, develop artistic language and aesthetic expression, and thus have a complete grasp of the creative process, as well as promote the development of sculpture art.

\section{References}

[1]Zhan Wang: Conceptual sculpture: Materialistic Concept. Art Research 3(1), 72-74 (1998)

[2]Qian Yunke: Talk about the Sculpture Material and the Sculpture. Sculpture 2(1), 53-55 (2007)

[3]Jean Robertson, Craig McDaniel: Themes of Contemporary Art Visual Art After 1980. USA OUP Publishers, (2005) 
[4]Sun Zhenhua: China Contemporary Sculpture. Hebei Arts Publishing Company, (2009)

[5]Jiao Xingtao: Contemporary Realism Sculpture. Chongqing Publishing Company, (2010)

[6]Chen Weihe: Highlights of Western Sculptures Before and After the Second World War. Hunan Arts Publishing Company, (1993) 